\title{
A EDUCAÇÃO DA CLASSE TRABALHADORA E O PNE (2014-2024) ${ }^{1}$
}

\section{N. RAMOS}

UERJ e EPSJV/Fiocruz

ramosmn@gmail.com

Artigo submetido em agosto/2016 e aceito em setembro/2016

DOI: $10.15628 /$ holos.2016.4982

\section{RESUMO}

Problematizamos a educação da classe trabalhadora no Brasil, especicificamente, parto de um balanço das conquistas que obtivemos nas últimas décadas. Interessou-nos, assim, captar o movimento histórico das relações sociais que levou a existência de determinadas leis e regulamentações, sabendo-se que esses podem conter possibilidades profícuas para a classe contrahegemônica.

PALAVRAS-CHAVE: Plano Nacional de Educação (2014-2024); educação da classe trabalhadora

\section{THE WORKING CLASS EDUCATION AND THE PNE (2014-2024)}

\section{ABSTRACT}

We discuss and question on the working class education. Precisely, we start at an evaluation of the conquers we achieved during the last decades. It matters to us, to catch the historical movement of the social relations that led to the existence of specific laws and regulations, once we know these can contain fruitful possibilities for the counter hegemonic class.

KEYWORDS: National Plan of Education (2014-2024); working-class education.

\footnotetext{
1 Texto base da conferência de abertura do III Colóquio Nacional A Produção de Conhecimento em Educação Profissional: o Plano Nacional de Educação, realizado no período de 04 a 07/08/2015, no IFRN, proferida em 04/08/2015.
} 


\section{INTRODUÇÃO}

Inicio esta análise afirmando que, ao nos referirmos à educação da classe trabalhadora, não tratamos apenas da educação profissional, mas sim de toda a educação a que esta classe tem o direito desde a infância. Por isto, parto de um balanço das conquistas que obtivemos nas últimas décadas. Tais conquistas são resultado de muitas lutas que expressam nossa capacidade de agirmos no movimento das contradições da relação entre capital e trabalho, ainda que sejam também atravessadas por derrotas e recuos.

Qualquer análise sobre o Plano Nacional de Educação poderia assumir alguns vieses. Um deles poderia ser exatamente o processo de elaboração, discussão e disputa que tomou lugar nas Conferências Nacionais de Educação, em diversos Seminários, nas associações científicas e no Congresso Nacional. Este, por exemplo, é um conteúdo abordado, de forma relativamente descritiva, pelo Relatório da Câmara dos Deputados (BRASIL, 2014a). Também este eixo é encontrado nos Cadernos da CNTE (CNTE, 2014) com a contribuição de muitos intelectuais da educação. Este texto, por sua vez, adotará como viés a análise de instrumentos jurídicos que consolidaram essa disputa.

Para isto, porém, é necessário salientar que um instrumento jurídico e/ou normativo - leis, decretos, resoluções, etc. - assim como documentos oficiais, expressam dimensões da luta social e de concepções em disputa, mas não se equiparam a realidade em si. Claro que esses documentos são concretos. Ou seja, conferem direção material à prática social, especialmente por seu caráter coercitivo. Por isto mesmo, eles são elaborados no e implementados a partir do Estado stricto sensu, o qual, nos termos ditos por Antônio Gramsci (1991), detém o monopólio legítimo da força. Simultaneamente, convertem-se numa condensação ideológica da correlação de forças entre as classes e frações de classe que disputam a hegemonia. São, portanto, instrumentos de hegemonia e/ou de contrahegemonia, pois, não tanto pela coerção, mas sim pelos consensos obtidos, seja entre esses grupos para se conseguir produzi-los; seja pelo convencimento e pelo consenso que eles conquistarão no seio da sociedade civil.

A este propósito, seria um equívoco pensar que a legislação e os documentos oficiais são emanados exclusiva e/ou prioritariamente a partir do Estado stricto sensu. Na verdade, na sociedade capitalista, qualquer tema que se constitua num objeto da regulamentação estatal surge de necessidades, confrontos, disputas e dissensos existentes no interior da sociedade civil em razão da luta de classes. As questões tornam-se então, matéria de regulamentação no interior do Estado, justamente por ser este uma relação entre sociedade civil e sociedade política. (GRAMSCl, 1991) Isto é, o Estado é a condensação material da correlação de forças entre as classes. (POULANTZAS, 1985)

Compreendo a legislação e os documentos oficiais por este prisma, não estranhamos o fato de este conter lacunas, silêncios e dubiedades. Essas ocorrem tanto devido às contradições reais das relações sociais, quanto de mecanismos e estratégias utilizadas pelas classes para se manter a disputa viva na dinâmica social na qual tais documentos poderão intervir. Por isto podemos afirmas que uma novo enfrentamento se inicia na sua materialização em ações práticas, pois estas serão produto de interpretações, apropriações e reapropriações do que o texto escrito pretende ou 
pretendia expressar. Falamos, então, das brechas da lei; das ressignificações, etc. que recompõem, no plano da sociedade civil, a luta por hegemonia.

Por essas mesmas razões afirmamos reiteradamente, que somente a conquista jurídica da possibilidade de se integrar a educação profissional ao ensino médio não era suficiente. Os caminhos a serem trilhados por essa possibilidade seriam traçados pela sociedade civil e não pelo Estado stricto sensu. A sociedade política havia cumprido sua função de mediar a articulação de interesses para não se inviabilizar a política pública ou reduzi-la a um ato de força. O mesmo precisaríamos dizer em relação à legislação subsequente, tais como a Emenda Constitucional $n$. 59/2009 (BRASIL, 2009) e o Plano Nacional de Educação (BRASIL, 2014b), por exemplo.

Em termos metodológicos, portanto, com base no pensamento histórico-dialético, não nos parece ser suficiente realizar a análise de conteúdo - saber o que é dito pelos documentos - ou de discurso - captar lógica de construção de significados pelo discurso - quando esses são abordados visando apreender a dinâmica da luta social instaurada na elaboração e na materialização de dispositivos jurídicos e normativos.

Não se trata, tampouco, de separar aparência e essência, como se os documentos fossem a aparência, a ideologia, o falseamento da realidade com vistas ao exercício da dominação, enquanto a essência seriam os interesses de classe que eles escondem e esta é que precisaria ser captada pela investigação. Se a limitação da pesquisa a procedimentos de análise tais como enunciados acima (especialmente do conteúdo numa tradição mais funcionalista) podem resvalar para o empiricismo, a análise que parte dessa separação pode tender a um certo essencialismo. A aparência é também constituinte do fenômeno e não o seu deliberado falseamento, pois, como nos diria Karel Kosik (1978), o fenômeno, ao mesmo tempo, manifesta e esconde a essência.

O que se busca, então, é captar o movimento histórico das relações sociais que levou a existência de determinadas leis e regulamentações, sabendo-se que esses podem conter possibilidades profícuas para a classe contrahegemônica. Interessam-nos, assim, contextos econômicos, sociais e políticos; disputas de grupos do mesmo campo ou opostos, estratégias de convencimento ou de manobras muitas vezes utilizadas, dentre outros aspectos. Trata-se de tentar captar mediações históricas constituintes dos fenômenos sociais, em relação aos quais os documentos são expressões parciais e condensadas. Em síntese, a legislação e os documentos oficiais não são, em si mesmos, a realidade, mas sim, a expressão de particularidades históricas que a compõem. Mesmo não sendo o espaço para se abordar as diversas mediações, é com esta referência que passamos à nossa análise.

\section{ANTECEDENTES HISTÓRICOS DO ATUAL PNE E ALGUMAS CONQUISTAS}

Ter a Constituição de 1988 como um marco na história da educação brasileira trata-se de um relativo consenso. A própria existência de um Plano Nacional de Educação decenal como um instrumento que estabelece princípios, metas e estratégias de ação decenais para a educação, e da Lei de Diretrizes e Bases da Educação Nacional, advém da Carta Magna. Esses foram instrumentos de superação do autoritarismo da classe dominante, ao qual as políticas públicas em geral e a educação em particular ficaram submetidos ao longo da ditadura civil-militar.

Testemunhamos a aprovação e a entrada em vigor do segundo PNE desse novo período com diferenças importantes em relação ao que o antecedeu. Registram-se, pelo menos, alguns 
avanços: a) sua elaboração contou amplamente com a participação da sociedade civil; b) determinou-se a vinculação do financiamento da educação a um percentual do PIB; c) previu-se a instituição do Sistema Nacional de Educação, inclusive mediante a regulamentação do regime de cooperação e colaboração entre os entes federados e as redes de ensino; d) formalizou-se o Fórum Nacional de Educação como integrante do sistema.

Tais avanços podem ser remetidos ao fato de o PNE 2014-2024 ter encontrado um contexto em que já vigoram algumas conquistas. No que se refere à educação básica, a emenda constitucional n. 59/2009 é significativa. Esta estabelece novas condições para o financiamento da educação, ao reduzir, anualmente, a partir do exercício de 2009, o percentual da Desvinculação das Receitas da União incidente sobre os recursos destinados à manutenção e desenvolvimento do ensino de que trata o art. 212 da Constituição Federal. Prevê, ainda, a obrigatoriedade do ensino de quatro a dezessete anos, além de ampliar a abrangência dos programas suplementares para todas as etapas da educação básica. Assim, as metas 1, 2 a 3, referentes, respectivamente às três etapas da educação básica, vislumbram a consecução do que foi antes determinado pela Emenda Constitucional.

No caso da educação infantil, sua universalização na pré-escola para crianças de quatro a cinco anos é prevista para 2016. Mesmo para a faixa etária não considerada obrigatória (zero a três anos), pretende-se ampliar a oferta em creches de forma a atender, no mínimo, cinquenta por cento dessa população até o final da vigência do PNE. Note-se que nenhuma referência é feita à esfera pública. Esta omissão, associada aos aspectos do financiamento disciplinados pelo parágrafo 4․ do artigo 5‥ da Lei que institui o Plano, o que abordaremos mais adiante, trará importante consequência para a questão da relação público e privado na educação. A definição de metas de expansão da oferta pelas redes públicas nesta etapa transformou-se em estratégia e, portanto, remetida a um tempo e processo não definidos.

Destaque deve ser dado à estratégia de se diminuir a desigualdade educacional produzida pela desigualdade social. É compreensível que um documento específico da educação remeta-se prioritariamente à desigualdade educacional e não necessária e diretamente, às respectivas determinações estruturais desta desigualdade que se manifestam de imediato, nas condições sociais da maioria da população brasileira. Não acomodar naturalmente a desigualdade em caminhos formativos duais e excludentes, defendendo-se, ao contrário, que esta não se reproduza no âmbito educacional, é legítimo e necessário. Preocupante, porém, é que ignorar suas determinações estruturais pode ser naturalizar a desigualdade social e apostar em supostos mecanismos de ascensão proporcionada pela escola, aos velhos moldes da Teoria do Capital Humano, renovada pela Pedagogia das Competências².

\footnotetext{
2 Vale à pena discutir a abordagem sobre a desigualdade educacional feita pelo Documento Pátria Educadora, elaborada pelo Secretário de Assuntos Estratégicos (SAE) do Governo Federal, Mangabeira Unger. Ele considera que a causa da desigualdade educacional está no fato de os alunos pobres possuírem "barreiras pré-cognitivas que os impedem de aceder às capacitações analíticas" (p. 6). Isto ocorre porque as famílias não conseguem desempenhar o seu papel de ensinar disciplinas aos seus filhos. Por isto, a escola teria que assumir parte das tarefas das famílias, criando espaços de estímulos e cobranças em turno social ampliado. Esta seria uma das principais razões para se estender o turno escolar. Conforme afirmamos em entrevista concedida a Cátia Guimarães, da Revista Poli (GUIMARÃES, 2015), o documento parte da ideia de que a família não pode cuidar. Transforma os problemas sociais em problemas individuais e os pedagogiza, convertendo um direito em um preceito seletivamente salvacionista.
} 
Aqui encontramos um exemplo do que falamos na introdução sobre diferentes interpretações de um mesmo texto, orientadas por distintas concepções de mundo. Se lermos o documento Pátria Educadora, vemos o quanto a infância tem sido disputada. Até bem pouco tempo esta era uma características do ensino médio, já que é onde está a juventude, é o momento em que os jovens tomam muitas decisões sobre sua vida, é quando se manifesta mais explicitamente a relação entre educação, trabalho e ciência, dentre outras. Particularidades essas, inclusive, que fazem o ensino médio ser um centro da discussão da educação politécnica. Ao lado disto, haveria certo consenso sobre as finalidades da educação infantil e do ensino fundamental. Enquanto o primeiro teria como propósito a socialização da criança, a preparação para a alfabetização, a introdução da criança na cultura letrada, etc., o ensino fundamental visaria consolidar a formação em termos das letras, das artes, da ciência e do prosseguimento de estudos para o ensino médio.

Atualmente, ainda que essas finalidades possam ser vistas com relativa clareza, vemos a centralidade que tem adquirido o desenvolvimento de competências sócio-emocionais e précognitivas, como pode ser visto no referido documento do governo brasileiro, além de outros nacionais e internacionais sobre a educação, difundifos por suas respectivas organizações, a exemplo de Unesco, OCDE, Instituto Ayrton Senna e Todos pela Educação, por exemplo. A infância, de fato, também está sendo disputada. Isto torna a luta pelo direito à educação ainda mais árdua, já que não se trata somente de se ter a universalização da educação básica, mas também de se discutir que infância, que adolescência, que juventude se quer e, por decorrência, que concepções de sociedade e de educação estão em disputa.

Vejamos, agora, as metas dois e três. A primeira visa universalizar o ensino fundamental de nove anos para toda a população de seis a quatorze anos e garantir que pelo menos noventa e cinco por cento dos alunos concluam essa etapa na idade recomendada, até o último ano de vigência deste PNE. A meta 3, por sua vez, relativa ao ensino médio, ainda não chega a prever índices de conclusão dos estudos nesta etapa, mas apenas o aumento da taxa média líquida de matrícula, para oitenta por cento, no período de vigência do Plano. Pretende-se, sim, universalizar 0 atendimento, condição fundamental para se atingir este índice.

As estratégias traçadas para a consecução desta meta concentram-se em aspectos curriculares, nos direitos e objetivos de aprendizagem, nos esforços para se garantir a formação básica comum, e em questões da juventude, incluindo o trabalho. Problematiza a comparabilidade dos sistemas de avaliação, considera a necessidade de correção de fluxo no ensino fundamental para o acesso ao ensino médio, bem como nesta mesma etapa e, finalmente, prevê o fomentar o aumento de matrículas gratuitas de ensino médio integrado à educação profissional. Ao soar positiva esta estratégia, deve-se, ao mesmo tempo, identificar um equívoco conceptual ao não se observar que é a educação profissional que deve se integrar ao ensino médio e não o contrário e, também, assinalar que a oferta gratuita de matrículas, atualmente são é sinônimo de expansão da oferta pública, tal como será falado adiante.

Também a forma integrada da educação profissional ao ensino médio não é sinônimo de formação integrada. Esta implica uma formação que integre as dimensões fundamentais da vida social dos estudantes ao currículo escolar - dimensões do trabalho, da ciência, da cultura, da tecnologia, dentre outras. Diferentemente disto, a forma integrada, muitas vezes acaba sendo um ajuste em termos de conteúdos e disciplinas de formação geral e profissional. Esta lógica tende a 
reiterar a Teoria do Capital Humano e reeditar aspectos da dualidade educacional e do tecnicismo e precisa ser superada.

A educação básica de jovens e adultos por sua vez, parece-nos ser tratada na perspectiva das funções reparadora e equalizadora abordadas pelas respectivas Diretrizes (BRASIL. MEC. CNE, 2000). Trata-se de elevar a escolaridade média para doze anos no período de vigência do plano, da população entre dezoito e vinte e nove anos (não abrangidas, portanto, pela obrigatoriedade educacional), para as populações do campo, da região de menor escolaridade no país, e dos vinte e cinco mais pobres e igualar a escolaridade média entre negros e não negros. A meta 9 também refere-se à população jovem e adulta - com idade superior a quinze anos - especificamente sobre a alfabetização $(93,5 \%$ até 2015 , fim do analfabetismo absoluto e redução de $50 \%$ do analfabetismo funcional até o final do Plano).

A articulação com a educação profissional atravessa as ações voltadas para a EJA, inclusive mediante o incentivo à oferta de matrículas gratuitas por entidades da sociedade civil, e se converte numa meta específica, a de número 10 , visando que $25 \%$ das matrículas da EJA nos ensinos fundamental e médio sejam ofertados de forma integrada à educação profissional. As estratégias preveem fomento a este tipo de oferta na formação inicial e continuada, com diversificação curricular, reconhecimento das especificidades desses sujeitos e com particular referência a população do campo e quilombolas. A parceria com instituições privadas é, novamente, prevista como estratégia.

A propósito, então, da relação entre educação básica e profissional, cabe lembrar que uma conquista neste campo também antecede a aprovação do atual Plano. Antes mesmo daquela emenda constitucional relevante para a política de educação básica da classe trabalhadora, a Lei n. 11.741/2008 (BRASIL, 2008) inclui na LDB a seção IV-A e os respectivos artigos que vão de 36-A a 36-D, que versam sobre a Educação Profissional Técnica da Nível Médio (BRASIL, 2008). Consolida-se, assim, o que havia sido conquistado pelo Decreto n. 5.154/2004 (BRASIL, 2004), que foi a articulação e, mais especificamente a possibilidade de integração com a educação profissional.

Esta incorporação amplia, ainda, o conceito para Educação Profissional e Tecnológica, ao revisar o capítulo III da lei. Essas medidas seguiram o princípio de que a educação dos trabalhadores voltada para o exercício do trabalho é indissociável da sua educação básica. Ou outras palavras, a educação da classe trabalhadora precisa ser a síntese unitária da educação básica e profissional, sob o princípio educativo do trabalho.

A síntese a que nos referimos não deve ser confundida com o aspecto exclusivamente formal da integração da educação profissional à educação básica. Na verdade, seguindo Gramsci (1991b), a integração entre educação escolar e trabalho na educação básica deveria ser mediata e não imediata. Discutimos em outros textos (RAMOS, 2010, 2013) que a relação imediata que se manifesta na possibilidade profissionalizante do ensino médio é, antes, expressão de uma necessidade social e não um princípio filosófico. Porém, por ser uma necessidade, acaba se constituindo em um problema ético nos termos que Nosella $(2008$, p. 257) nos traz do pensamento de Gramsci: "a cada momento histórico o homem se propõe novos problemas. Existindo as condições técnicas para sua solução, a possibilidade de resolvê-los torna-se uma opção, um dever, isto é, uma questão ética". 
Assim, a possibilidade de a educação profissional ser integrada à educação básica torna-se uma ação objetiva e ética para resolver um problema concreto da classe trabalhadora brasileira, para o que a sociedade brasileira possui pelas condições técnicas.

Ao mesmo tempo, a experiência exitosa das antigas Escolas Técnicas Federais nesse sentido mostrou que nela estavam perspectivas de superação da dualidade educacional e os germens de uma educação poltécnica. (SAVIANI, 1997) Talvez aqui possamos identificar uma efetiva integração entre teoria e prática do sentido da práxis. Ou seja, uma teoria vigorosa como o materialismo histórico-dialético nos permite entender as contradições do real (a dualidade educacional da educação da classe trabalhadora), projetar sua superação (a educação unitária, politécnica e omnilateral) e construí-la por mediações da realidade concreta (o ensino médio integrado). 0 utópico, então, se constrói a partir do real e não o contrário.

Nossa utopia, portanto, seria o ensino médio não profissionalizante, assim como a EJA deixaria de ser uma modalidade da educação básica destinada àqueles que a ela não tiveram acesso em idade apropriada e convergiria com a educação continuada. Porém, em ambos os casos, a integração da educação profissional à educação básica é uma mediação para a construção da utopia. Sendo assim, a concepção do currículo que integre trabalho, ciência e cultura na formação dos estudantes, sob o princípio educativo do trabalho, abrange todo o ensino médio, tenha ou não a educação profissional a ele formalmente integrada. O dia em que a necessidade desta integração formal for superada, talvez tenhamos a utopia construída e o ensino médio será "integrado" como concepção de formação humana e não como mediação política, porque o problema social e ético, terá sido revido. Teremos, pois, outra sociedade.

Confrontadas com essa concepção, talvez as conquistas aqui discutidas não tenham ultrapassado a barreira do economicismo e do tecnicismo. Porém, tem-se ao menos que a educação nacional seja organizada sob alguns princípios fundamentais. Por exemplo, o princípio da obrigatoriedade exige que toda criança a partir dos quatro anos de idade esteja na educação básica, sob a responsabilidade dos pais e do poder público de garantir esta condição. Este direito e a correspondente obrigação perduram até os 17 anos de idade do estudante.

Ao disciplinada pela idade e não pelos anos de escolaridade, a obrigatoriedade não resolve o problema da defasagem idade-série, normalmente deflagrada na evasão e na persistência de índices da população adulta sem completar a educação básica. Mesmo assim, tem-se aqui uma conquista. Ademais, a educação profissional não se torna uma formação à parte e independente da educação básica, mas deve ser articulada e até mesmo integrada a esta.

\section{O FINANCIAMENTO DA EDUCAÇÃO NO PNE: A DIFÍCIL SUPERAÇÃO DA HEGEMONIA PRIVATISTA}

Mecanismos importantes para a materialização dessas medidas, incluindo os de financiamento da educação e de permanência do estudante na escola, também foram proporcionados pela emenda 59/2009. Como assinalamos, tem-se a redução do percentual de desvinculação de receitas da união que afetam os recursos constitucionalmente destinados à educação e a ampliação dos programas suplementares para além do ensino fundamental.

Essas conquistas, no lastro das lutas históricas pelo aumento do financiamento da educação, foram se tornando motivos concretos para alguns avanços vistos no atual PNE. 
Manifestação disto é a inclusão, no artigo 20 do plano a inclusão da diretriz VIII - estabelecimento de meta de aplicação de recursos públicos em educação como proporção do Produto Interno Bruto (PIB), que assegure atendimento às necessidades de expansão, com padrão de qualidade e equidade.

Esta diretriz redundou na Meta 20 do plano, que prevê ampliar o investimento público em educação pública, de forma a atingir, no mínimo, o patamar de sete por cento do Produto Interno Bruto (PIB) do país no quinto ano de vigência da lei e, no mínimo, o equivalente a dez por cento do PIB ao final do decênio. A garantia de que o investimento público fosse em educação pública foi fruto de uma disputa muito acirrada na sociedade e, em particular, entre as visões que se manifestaram na Câmara dos Deputados e no Senado Federal. A versão que permaneceu foi a defendida pelos educadores críticos.

Porém, o artigo 5․ do Plano, cujo caput dispõe sobre o monitoramento contínuo e de avaliações periódicas da execução do PNE e respectivo cumprimento de metas por órgãos do executivo, legislativo e da sociedade civil, em seu parágrafo 4으, assim apregoa:

o investimento público em educação a que se referem o inciso IV do artigo 214 da $\mathrm{CF}^{3}$ e a meta 20 do anexo desta lei engloba os recursos aplicados na forma do artigo 212 da $\mathrm{CF}^{4}$ e do artigo 60 do $\mathrm{ADCT}^{5}$, bem como os recursos aplicados no Programa de Expansão da Educação Profissional e superior, inclusive na forma de incentivo e isenção fiscal, as bolsas de estudo concedidas no Brasil e no exterior, os subsídios concedidos em programas de financiamento estudantil e o financiamento de creches, pré-escolas e educação especial, na forma do artigo 213 da CF. (BRASIL, 2014b)

O Documento Referência do PNE da Câmara dos Deputados (BRASIL, 2014a) relata ter havido destaque supressivo em relação a este parágrafo, mas, ao final, a votação foi por sua permanência. Assim, tornou-se possível contabilizar os recursos de isenções fiscais que financiam programas como o Prouni e o Pronatec, ou os empréstimos que compõem o Fies na meta de investimento público em educação.

Análises já publicadas sobre o Plano ${ }^{6}$ argumentam que esse texto está em contradição com o que diz a Meta 20, que prevê aplicar 10\% do PIB em educação pública. O que está inscrito na Meta 20 seria equivalente a afirmar que devem ser alcançados $10 \%$ do PIB no chamado "Investimento Direto em Educação", definido como o conjunto de recursos usados pelo Estado exclusivamente em escolas mantidas pelos governos, em todos os níveis. Em 2012, esse percentual teria sido de $5,5 \%$ do PIB. Se, ao contrário, forem computados nos recursos aplicados todos os

\footnotetext{
${ }^{3}$ Refere-se ao estabelecimento de meta de aplicação de recursos públicos em educação como proporção do produto interno bruto."(insciso acrescentado pelo art. 5ㅇ da Emenda Constitucional no 5/9/2009 ao artigo 214, o qual determina o estabelecimento do PNE por lei, com duração decenal).

${ }^{4}$ A União aplicará, anualmente, nunca menos de dezoito, e os Estados, o Distrito Federal e os Municípios vinte e cinco por cento, no mínimo, da receita resultante de impostos, compreendida a proveniente de transferências, na manutenção e desenvolvimento do ensino.

${ }^{5}$ Até o 14ㅇ (décimo quarto) ano a partir da promulgação desta Emenda Constitucional, os Estados, o Distrito Federal e os Municípios destinarão parte dos recursos a que se refere o caput do art. 212 da Constituição Federal à manutenção e desenvolvimento da educação básica e à remuneração condigna dos trabalhadores da educação, respeitadas as seguintes disposições (redação dada pela EC n. 53/2006)

${ }^{6}$ Baseamo-nos particularmente à análise extraída de http://proifes.org.br/noticia/927/uma-analise-preliminar-dealgumas-questoes-relevantes-no-relatorio-do-deputado-angelo-vanhoni-referente-ao-plano-nacional-de-educacao. Consulta em 03 de agosto de 2015
} 
gastos estatais em educação pública ou privada - continua a análise - o que incluiria bolsas de estudo, renúncia fiscal para escolas e universidades, etc., estar-se-ia, então falando em "Investimento Total em Educação", um conceito muito diferente. No ano de 2012 este montante teria sido de 6,4\% do PIB, portanto já próximo ao que se prevê para 2019.

Com clareza, a matéria em que estamos nos baseando mostra como esta incongruência tem consequências graves: em cinco anos, com base na Meta 20, deveríamos passar dos 5,5\% do PIB de Investimento Direto em Educação ocorridos em 2012 para 7\% do PIB; já com base no Art. 5 o da Lei deveríamos aumentar o Investimento Total em Educação de 6,4\% do PIB (2012) para 7\% do PIB.

Além de levarem a conclusões diferentes - já que a primeira significa um adicional de 1,5\% do PIB, enquanto a segunda, 0,6\% do PIB -, os recursos do aplicados no Prouni e no Pronatec, além do Fies (também este, no ensino superior e na educação profissional), não são destinados exclusivamente a instituições públicas. Tanto no primeiro caso - por ser essencialmente a destinação de vagas de ensino superior em instituições privadas -, quanto no segundo, por intermédio do componente bolsa-formação e do Fies-Técnico - predomina o apoio a instituições privadas.

Assim, só estará garantida a destinação de uma parcela desses novos recursos ao setor público da educação técnica de nível médio e do ensino superior, devido às metas 11 e 12 . A primeira prevê triplicar a oferta de matrículas da educação profissional técnica de nível médio, assegurando a qualidade, assegurando a qualidade da oferta e pelo menos $50 \%$ da expansão no setor público. A segunda aponta para a elevação da taxa bruta de matrículas no ensino superior para cinquenta por cento e a taxa líquida para trinta e três por cento, da população de dezoito a vinte e quatro anos, assegurada a qualidade e a expansão para, pelo menos, quarenta por cento das novas matrículas no segmento público.

Em contraposição, os recursos adicionais a serem investidos pelo Estado em creches, préescola ou educação especial - por exemplo - podem ser integralmente direcionados ao setor privado, sendo as correspondentes matrículas expandidas apenas nesse segmento, com vistas ao cumprimento das metas propostas.

Se iniciamos nossas considerações afirmando que trataríamos da educação da classe trabalhadora não somente na educação profissional, vimos aqui uma contradição brutal do atual PNE por intermédio do qual o Estado incentivaria a expansão da formação de crianças, incluindo filhos da classe trabalhadora, em instituições privadas. A formação profissional e de nível superior de jovens e adultos no segmento público, por sua vez, será fomentada apenas parcialmente.

\section{UM RETRATO DA EDUCAÇÃO PROFISSIONAL (2003-2014) E A RELAÇÃO COM O PNE}

Falávamos das conquistas que pavimentaram avanços identificados no atual PNE. Certamente, a inclusão de uma meta explicitamente relativa à educação profissional técnica de nível médio, prevendo, ainda, a expansão de pelo menos $50 \%$ no setor público é positiva.

Durante os anos de 1990 aos 2000, grande parte da oferta da Educação Profissional no Brasil foi assumida pela sociedade civil, principalmente por adesão ao Programa de Expansão da Educação Profissional - PROEP, do Ministério da Educação. De fato, os dados do Censo de 2003 
demonstraram que a oferta de educação profissional pelo setor privado àquela época correspondia a 55\%, superando, então, a oferta pública. (INEP, 2003) Recentemente, como demonstra a mesma base de dados (INEP, 2014), essa relação se inverteu, de modo que entre 2011 e 2013, a oferta nessa esfera está em torno de 53\%. Contribui para este índice a predominância das redes federal, estadual e municipal na oferta da educação profissional integrada ao ensino médio (92\% ao todo nos três anos), ao passo que a educação profissional não integrada ao ensino médio continua sendo ofertada predominantemente pela esfera privada (56,3\% em $2011 ; 57 \%$ em 2012; 60,3\% em 2013).

A mudança deste quadro, vista a partir da política do governo federal, se deve à tentativa de se reconstruir esta política pública, a partir de 2003, pelo menos nos seguintes sentidos: a) revogar o decreto n. 2.208/97, restabelecendo a possibilidade de integração curricular dos ensinos médio e técnico, de acordo com o que dispõe a Lei de Diretrizes e Bases da Educação Nacional (LDB); b) expandir a educação profissional e tecnológica na esfera pública, com recursos públicos. O primeiro propósito levou à exaração do decreto n. 5.154/2004 e à incorporação de seu conteúdo à LDB. O segundo ocorreu com a aprovação da Lei n. 11.195/2005 (BRASIL, 2005), que alterou o § 5‥ artigo $3^{\circ}$ da Lei 8.948/94, possibilitando novamente a criação de novas unidades de ensino por parte da União.

Os avanços políticos possibilitados por essas novas regulamentações, expressos principalmente na expansão da rede federal, no apoio aos sistemas estaduais para a oferta da educação profissional - especialmente na forma integrada ao ensino médio - e no acordo de gratuidade com o Sistema S, sofreram um refluxo a partir da instituição do Pronatec. Este tende a priorizar a oferta da formação inicial e continuada e a incentivar a atuação da esfera privada na educação profissional com subsídios públicos. Tal constatação é demonstrada mediante análise de alguns dados de financiamento e de matrículas obtidos em fontes governamentais oficiais.

O Programa foi lançado em entrevista coletiva dada pelo Ministro da Educação, no dia 13 de abril de 2011. O projeto de Lei do PNE apresentado pelo poder executivo ao Congresso Nacional ainda em 2010 já apresentava algumas medidas que referendariam o Pronatec, algumas das quais estão consolidadas no Plano aprovado, especialmente como estratégias da meta 11, relativa especificamente à educação profissional e, ainda, na meta 10 , relativa à oferta da educação profissional integrada à educação básica na modalidade EJA.

A lei n. $12.513^{7}$ criou efetivamente o Programa no dia 26 de outubro de 2011 (BRASIL, 2011), cujo objetivo principal seria expandir, interiorizar e democratizar a oferta de cursos de Educação Profissional e Tecnológica para a população brasileira. Além de incorporar os programas já existentes, a ação diferencial do Pronatec foi proporcionar, com subsídio público, o acesso de estudantes e trabalhadores a vagas de educação profissional técnica de nível médio e de formação inicial e continuada em instituições privadas.

\footnotetext{
${ }^{7}$ Institui o Programa Nacional de Acesso ao Ensino Técnico e Emprego (Pronatec); altera as Leis no 7.998 , de 11 de janeiro de 1990, que regula o Programa do Seguro-Desemprego, o Abono Salarial e institui o Fundo de Amparo ao Trabalhador (FAT), no 8.212, de 24 de julho de 1991, que dispõe sobre a organização da Seguridade Social e institui Plano de Custeio, no 10.260, de 12 de julho de 2001, que dispõe sobre o Fundo de Financiamento ao Estudante do Ensino Superior, e no 11.129, de 30 de junho de 2005, que institui o Programa Nacional de Inclusão de Jovens (ProJovem); e dá outras providências.
} 
O Pronatec é composto, então, por programas que já existiam, a saber: a) expansão da Rede Federal de EPT ${ }^{8}$; b) Brasil Profissionalizado; c) E-TEC Brasil; d) Acordo de Gratuidade Sistema S; e das seguintes ações: a) Bolsa-Formação Estudante e Trabalhador, esta última nas modalidades Seguro-Desemprego e Inclusão Produtiva; b) FIES Técnico Estudante e Empresa; c) ampliação da Capacidade do Sistema S.

A legitimidade que o atual Plano Nacional de Educação confere a esta política pode ser constatada na tabela que faz correspondência entre as estratégias e as políticas:

Tabela 1: Relação entre estratégias do PNE para a educação profissional e as políticas e ações desenvolvidas pelo governo federal

\begin{tabular}{|c|c|}
\hline Estratégia & Política/Ação \\
\hline $\begin{array}{l}\text { 11.1. Expandir as matrículas de educação profissional técnica de nível médio } \\
\text { na Rede Federal de Educação Profissional, Científica e Tecnológica, levando } \\
\text { em consideração a responsabilidade dos institutos na ordenação territorial, } \\
\text { sua vinculação com arranjos produtivos, sociais e culturais locais e } \\
\text { regionais, bem como a interiorização da educação profissional. }\end{array}$ & $\begin{array}{l}\text { Plano de expansão da } \\
\text { Rede Federal }\end{array}$ \\
\hline $\begin{array}{l}\text { 11.2. Fomentar a expansão da oferta de educação profissional técnica de } \\
\text { nível médio nas redes públicas estaduais de ensino. }\end{array}$ & $\begin{array}{l}\text { Programa Brasil } \\
\text { Profissionalizado }\end{array}$ \\
\hline $\begin{array}{l}\text { 11.3. Fomentar a expansão da oferta de educação profissional técnica de } \\
\text { nível médio na modalidade de educação a distância, com a finalidade de } \\
\text { ampliar a oferta e democratizar o acesso à educação profissional pública e } \\
\text { gratuita, assegurado padrão de qualidade; }\end{array}$ & E- TEC \\
\hline $\begin{array}{l}\text { 11.5. Ampliar a oferta de programas de reconhecimento de saberes para fins } \\
\text { de certificação profissional em nível técnico; }\end{array}$ & Rede Certific \\
\hline $\begin{array}{l}\text { 11.6. Ampliar a oferta de matrículas gratuitas de educação profissional } \\
\text { técnica } \\
\text { de nível médio pelas entidades privadas de formação profissional vinculadas } \\
\text { ao sistema sindical e entidades sem fins lucrativos de atendimento } \\
\text { à pessoa com deficiência, com atuação exclusiva na modalidade. }\end{array}$ & $\begin{array}{l}\text { Bolsa-Formação; Bolsa- } \\
\text { Trabalhador }\end{array}$ \\
\hline $\begin{array}{l}\text { 11.7. Expandir a oferta de financiamento estudantil à educação profissional } \\
\text { técnica de nível médio oferecida em instituições privadas de educação } \\
\text { superior. }\end{array}$ & $\begin{array}{l}\text { FIES-Técnico; FIES- } \\
\text { Empresa }\end{array}$ \\
\hline
\end{tabular}

Fonte: elaboração própria.

Em 2012, este programa teria abrangido 2,5 milhões de matrículas e, até 2014 previa-se a oferta de 8 milhões de vagas em todo o país. Relatório de gestão da SETEC de 2013 (BRASIL. MEC. SETEC, 2013) demonstra que, entre 2011 e 2013 foram ofertadas o total de 2.854.208 vagas pelo Pronatec, sendo 766.580 para cursos técnicos e 2.087.628 vagas para cursos Fic (incluindo todos os subprogramas do Pronatec: Bolsa Formação, Brasil Profissionalizado, e-Tec, Acordo Sistema S e Rede Federal de EPTC, no caso dos cursos técnicos; e Bolsa Formação e Acordo Sistema S para os Fic). Para era 2014 é previsto um total de 3.104.936 vagas, sendo 897.643 para os cursos técnicos e 2.207.293 para os cursos Fic. A tabela abaixo resume este cenário.

\footnotetext{
8 Sugerimos leitura do documento Expansão da rede federal. Disponível em: <http://redefederal.mec.gov.br/index.php?option=com_content\&view=article\&id=52\&ltemid=2> Acesso em: 06/01/2012.
} 
Tabela 2: Oferta de vagas pelo Pronatec nas respectivas formas de oferta da Educação Profissional.

\begin{tabular}{|c|c|c|}
\hline & $\mathbf{2 0 1 1 - 2 0 1 3}$ & Previsão 2014 \\
\hline Cursos Técnicos & $766.580(27 \%)$ & $897.643(29 \%)$ \\
\hline Cursos FIC & $\begin{array}{c}2.087 .628(73 \%) . \\
\text { Incluindo todos os subprogramas }\end{array}$ & $2.207 .293(71 \%)$ \\
\hline TOTAL & $2.854 .208(100 \%)$ & $3.104 .936(100 \%)$ \\
\hline
\end{tabular}

Fonte: elaboração própria.

Os dados nos mostram que o Programa, em 2014, poderia chegar perto de $40 \%$ da meta prevista, na proporção de $29 \%$ de vagas para cursos técnicos e $71 \%$ para cursos Fic. Fica claro que o Pronatec prioriza a expansão da formação inicial e continuada de trabalhadores e não da formação técnica de nível médio.

A estratégia desse tipo de expansão é o Bolsa-Formação Trabalhador destinada a estudantes de cursos de formação inicial e continuada (cursos FIC, com o mínimo de 160 horas). Existe, ainda, o Bolsa-Formação Estudante, para oferta de cursos de educação profissional técnica de nível médio (cursos técnicos).

Podem ser beneficiados por este subprograma os seguintes sujeitos: estudantes do ensino médio da rede pública, inclusive da educação de jovens e adultos; trabalhadores; beneficiários titulares e dependentes dos programas federais de transferência de renda ${ }^{9}$; pessoas com deficiência; povos indígenas e quilombolas; adolescentes e jovens em cumprimento de medidas socioeducativas; trabalhadores beneficiários do seguro-desemprego, considerados reincidentes, estudantes que tenham concluído o ensino médio completo em escola da rede pública ou em instituições privadas na condição de bolsista integral ${ }^{10}$.

Em 2013, conforma consta do mesmo relatório, o Bolsa-Formação foi o maior responsável pela oferta de vagas nos cursos Fic (60\%) e por uma significativa parcela dos cursos técnicos (40\%). Ressaltamos tais informações porque este subprograma possibilita a transferência de recursos públicos para a esfera privada. A previsão para 2014 propôs alterar um pouco este quadro, na medida em que se previa a redução da participação do Bolsa-Formação em ambos os casos (metas de $45 \%$ das vagas ofertadas para os Fic e de $17 \%$ para os cursos técnicos). Nesse ano, então, os

\footnotetext{
9 Podemos nos referir ao Pronatec Brasil Sem Miséria, com mais de 266 mil beneficiários de Programas Federais de Transferência de Renda matriculados; o Pronatec Seguro Desemprego, que alcançou mais de 48 mil beneficiários; e mais de 221 mil estudantes do ensino médio público atendidos. (BRASIL. MEC.SETEC, 2012)

${ }^{10}$ Constam como agentes de implementação do Bolsa-Formação: a) SETEC/MEC; b) FNDE/MEC/ c) Instituições da Rede Federal de EPT; d) Instituições de EPT das redes estaduais; e) Instituições do Sistema S; f) Instituições privadas de ensino superior e de EPT habilitadas para a oferta de cursos técnicos na modalidade subsequente. As instituições listadas a partir do item (c) se configuram como ofertantes e devem assinar o Termo de Adesão ao Programa. Além dessas, também são agentes de implementação da Bolsa as secretarias estaduais e distrital de educação, bem como Ministérios e outros órgãos da Administração Pública Federal, na condição de demandantes. Os cursos ofertados mediante pactuação entre demandantes e ofertantes devem ser registrados no SISTEC.

Tal como disciplinado na Lei n. 12.816, de 05/06/2013 (BRASIL, 2013), os valores das bolsas-formação correspondem ao custo total do curso por estudante, incluídos mensalidades, encargos educacionais e custeio de transporte e alimentação, vedada cobrança direta aos estudantes de taxas de matrícula, custeio de material didático ou qualquer outro valor pela prestação do serviço. O montante de recursos corresponde ao número de vagas pactuadas por cada instituição de ensino ofertante, que são posteriormente confirmadas como matrículas no SISTEC, observada a obrigatoriedade de devolução de recursos em caso de vagas não ocupadas.
} 
subprogramas compreendidos pela esfera pública aumentariam relativamente sua presença: no caso dos cursos Fic, 55\% da oferta de vagas ocorreria pelo Acordo Sistema S.

Com respeito aos cursos técnicos, enquanto em 2013 a menor oferta ocorreu pelo Brasil Profissionalizado (9\%), em 2014 esta passaria para 26\%. A maioria das vagas seria ofertada na modalidade a distância (28\%). A rede federal e o acordo Sistema S responderiam, respectivamente, por $18 \%$ e $11 \%$ das vagas.

Mesmo com esta relativa inversão, o Pronatec conta com outra estratégia de financiamento público de matrículas em instituições privadas: o Fies Técnico e o Fies Empresa. Trata-se do Fundo de Financiamento Estudantil destinado a financiar cursos técnicos e cursos de formação inicial e continuada ou de qualificação profissional para estudantes e trabalhadores, em caráter individual, em instituições de ensino privadas e nos serviços nacionais de aprendizagem. O Fies Empresa, por sua vez, é o financiamento concedido a empresas para custeio da formação inicial e continuada ou qualificação profissional dos seus trabalhadores.

Como pudemos ver na tabela 1, essa ação é legitimada pela estratégia 11.7 do atual PNE, que visa expandir a oferta de financiamento estudantil à educação profissional técnica de nível médio oferecida em instituições privadas de educação superior. Conforme dispõe a Portaria n. 160, de 05/03/2013 (BRASIL, 2013), para ofertar cursos de educação profissional técnica de nível médio e, ainda cursos de formação inicial e continuada ou de qualificação profissional no âmbito do Pronatec, as instituições privadas de ensino superior e de educação profissional técnica de nível médio devem ser previamente habilitadas pelo Ministério da Educação, e suas mantenedoras deverão fazer a adesão ao Programa, conforme as normas estabelecidas na mesma Portaria.

Neste cenário, o acordo de gratuidade com o Sistema $S^{11}$ é um contraponto importante. Porém, é notória a diferença entre o número de matrículas da formação inicial e continuada e da formação técnica de nível médio ofertada por este acordo que podemos captar no relatório da SETEC. Esta última, em 2013, correspondeu a somente $13,5 \%$ da oferta no nível anterior e, em 2014, a previsão foi de $12 \%$. Portanto, são para os cursos mais baratos que a gratuidade é ampliada.

A tendência de não se privilegiar a oferta da educação profissional técnica de nível médio vem acompanhada de outros fatos. O primeiro deles é que a expansão nesse nível da educação profissional não tende a ocorrer na forma integrada. O quadro de expansão de matrículas dos cursos técnicos (considerando as formas subsequente, concomitante e integrada ao ensino médio), no triênio de 2011 a 2013, é o seguinte: 1.250 .900 matrículas em 2011, 1.362 .200 matrículas em 2012 e 1.441 .051 em 2013. (BRASIL. INEP, 2014) Porém, enquanto as matrículas dos cursos concomitantes e subsequentes cresceram em 7\% de 2011 para 2012 e, no ano seguinte, em 37\%, chegando-se a 1.102 .661 em 2013, no caso da educação profissional integrada ao ensino médio, a evolução nos mesmos períodos variou somente para 15 e para 13 pontos percentuais, totalizando, em 2013, 338.390 matrículas.

O segundo fato é que a expansão de cursos técnicos concomitantes e subsequentes concentram-se na esfera privada (60,3\%). No caso dos cursos integrados ao ensino médio, são as

\footnotetext{
${ }^{11}$ Este acordo tem por objetivo ampliar, progressivamente, a aplicação dos recursos do SENAI, do SENAC, do SESC e do SESI, recebidos da contribuição compulsória, em cursos técnicos e de formação inicial e continuada ou de qualificação profissional, em vagas gratuitas destinadas a pessoas de baixa renda, com prioridade para estudantes e trabalhadores.Informação disponível em <http://pronatec.mec.gov.br/institucional-90037/objetivos-e-iniciativas> . Consultado em 07/04/2014.
} 
redes públicas que predominam (92\%). (BRASIL. INEP, 2014) A presença das redes privadas na oferta de cursos Fic também é significativa, uma vez que aproximadamente a metade é apoiada pelo Bolsa-Formação (a outra está no acordo Sistema S), e seus recursos podem ser transferidos para instituições dessas redes.

Se demonstramos que a expansão da educação profissional no país ocorre, até então, na proporção de $29 \%$ de vagas para cursos técnicos e $71 \%$ para cursos Fic; que, no caso dos cursos técnicos, a Bolsa-Formação também pode financiar a oferta privada; e que a forma na qual se destaca a presença das redes públicas (integrada ao ensino médio) não é a que mais se expande, poder-se-ia deduzir que a política de educação profissional no país atual se volta predominantemente para o fortalecimento da esfera privada?

Esta análise não é conclusiva. Porém, algumas informações valem como pistas para a sua continuidade e para a construção de questões políticas e de pesquisa. Uma delas surge do SISUTEC - Sistema de Seleção Unificada da Educação Profissional e Tecnológica - um sistema informatizado gerenciado pelo MEC no qual instituições públicas e privadas de ensino superior e de educação profissional e tecnológica oferecem vagas gratuitas em cursos técnicos na forma subsequente para candidatos participantes do Exame Nacional do Ensino Médio (Enem) ${ }^{12}$, instituído pelo MEC em 2013. Da relação de instituições que ofereciam vagas neste ano, havia uma quantidade significativa que eram privadas ${ }^{13}$.

No Estado do Rio de Janeiro, por exemplo, as aproximadamente 40 mil vagas ofertadas pelo Pronatec (no Brasil são 291.338 vagas) em 2014 por este sistema advêm de grandes empresas da educação, tais como a Universidade Estácio de Sá (29.840 vagas), a Unicarioca (1.040 vagas), e o Centro Universitário Anhaguera (2.360 vagas), sem falar das 7.245 vagas oferecidas pelo SENAI$\mathrm{RJ}^{14}$. Para efeitos de comparação, o CEFET-RJ oferece anualmente menos de duas mil vagas para cursos técnicos. Em termos de repasse de recursos, dados do MEC de 2011, que constam da Portaria n. 324/2011 (BRASIL. MEC. SETEC, 2011) demonstram que 92\% dos recursos repassados nesse ano às instituições parceiras foram para o SENAC e o SENAI. O restante foi dividido por dez Institutos Federais, para a UFRN e para o Colégio Pedro II.

Outra fonte interessante é a reportagem de Cátia Guimarães (2014) na Revista Poli (EPSJV/FIOCRUZ). Segundo a matéria, o grupo Anhanguera-Kroton - considerada a maior empresa educacional do mundo - tinha, no primeiro semestre de 2014, 35 mil alunos em cursos técnicos e possibilidade de ampliar em 28.104 matrículas até o final do referido ano. Ainda segundo a reportagem, o grupo Estácio - o segundo maior no ranking das instituições de ensino superior "já tem este ano [2014] quase 25 mil matrículas - e, neste caso, todas no Rio de Janeiro, estado em que as IES privadas vão oferecer 4,5 vezes mais vagas de cursos técnicos do que o Senai" (GUIMARÃES, 2014a, p. 15).

Esses dados objetivos analisados face ao parágrafo 4ㅇ. do artigo 5․ da Lei do Plano comprovam que, mesmo tendo conquistado, na meta 20, a garantia de que o investimento público seria na educação pública, a redação da lei conseguiu proteção para a transferência de recursos públicos à iniciativa privada. Isto porque analisamos exclusivamente a política de educação profissional. Certamente uma análise da educação superior nos daria ainda mais provas desta

\footnotetext{
12 Disponível em <http://sisutec.mec.gov.br>. Consulta em 20/08/2013.

${ }^{13}$ Até o momento de conclusão deste texto não nos foi possível fazer levantamento estatístico desses dados.

${ }^{14}$ Informações obtidas em levantamento feito informalmente pelo Prof. Carlos Artexes Simões.
} 
incoerência e do oportunismo que acabou tendo lugar na lei, entre avanços e recuos que são expressões da luta social.

Parece-nos que o governo federal escolhe um caminho, entre outros possíveis, para o fortalecimento da educação profissional no país. Todas as ações induzem para a expansão da educação profissional técnica de nível médio de forma concomitante ou subsequente em todas as redes e da formação inicial e continuada. Esta opção converge com outra, a saber: o incentivo à participação do empresariado da educação e a transferências de recursos públicos para o setor privado $^{15}$.

É bem verdade que a ampliação da Rede Federal continua sendo um subprograma do Pronatec, como a Fase III do Plano de Expansão. Até $2020^{16}$, seriam implantadas 60 novas unidades de ensino a cada ano, levando a Rede Federal à configuração de 1.000 unidades ao final desta década. Fica a questão sobre a possibilidade de um crescimento de matrículas nesta rede, até 2014, ser capaz de agregar vagas públicas à educação profissional no país. Diante do exposto, caberia perguntar com que projeto de sociedade e de desenvolvimento a política de educação profissional é convergente.

\section{CONSIDERAÇÕES FINAIS}

Este texto procurou fazer um balanço de avanços e conquistas na política de educação da classe trabalhadora no Brasil nas duas últimas décadas, discutindo também limites, derrotas e recuos. Partimos do reconhecimento de que os anos de 1980 representam um marco histórico em nosso país porque, mesmo não nascendo de relações democráticas plenas, a Constituição de 1988 abriu espaço nos planos ético, político e jurídico, para avançarmos na política educacional, assim como as pesquisas em Educação nos possibilitou acesso a conhecimentos que nos permitiram analisar a educação da classe trabalhadora como espaço de luta por hegemonia por ser eivado de contradições.

Consideramos que a existência tanto da LDB quanto do Plano Nacional de Educação devemse a essa dinâmica social. Não retomamos aqui explicitamente a derrota que sofremos pela não aprovação do Projeto de LDB original da Cãmara dos Deputados, o qual representava uma nova perspectiva para a educação brasileira, especialmente por assentar a concepção de educação básica sob os princípios da educação unitária, politécnica e omnilateral. Foi exatamente a exclusão desses princípios e uma lógica minimalista assumida pela lei aprovada em 1996 que contribuiu para que reformas educacionais de cunho neoliberal, que atingiram frontalmente direitos da classe trabalhadora, fossem realizadas intensamente nos governos de Fernando Henrique Cardozo.

O primeiro Plano Nacional de Educação aprovado no mesmo contexto tampouco se comprometeu com as necessidades dessa classe. Ao contrário, de tão débil, acabou levando a política de educação para os balcões de negócios. O Programa de Desenvolvimento da Educação

\footnotetext{
15 É digno de nota o fato de a meta 11 do atual PNE, de triplicar a oferta da educação profissional técnica de nível médio, prever que se assegure a qualidade da oferta e pelo menos $50 \%$ (cinquenta por cento) da expansão no segmento público.

${ }^{16}$ Seria necessário saber se tais metas seriam ou não replanejadas para o período de vigência real do plano, que se iniciou em 25/06/2014.
} 
(PDE) e o "Todos pela Educação", já no governo seguinte, vieram no lastro dessa debilidade do Plano.

Diferentemente, como afirmamos, o atual PNE, cuja discussão no Congresso Nacional e na sociedade atravessou quatro anos, contou com a participação da sociedade civil e buscou resgatar alguns dos princípios defendidos na discussão da LDB, a exemplo da definição do Sistema e do Fórum Nacionais de Educação. Em razão da necessidade de se organizar o Sistema Nacional de Educação, reconheceram-se lacunas a serem superadas, como a regulamentação do regime de colaboração e cooperação entre os sistemas e as redes de ensino. A luta histórica de atrelamento do financiamento da educação a um percentual do PIB também foi contemplada na lei do atual PNE, além da implantação do Custo Aluno Qualidade. Destaque-se o enunciado de princípios de redução de desigualdades regionais, étnicas e raciais na educação.

Mesmo em relação à concepção de educação básica como unitária, politécnica e de formação omnilateral, considerando as devidas contradições e dubiedades que atravessam a atual política, a incorporação, tanto na LDB quanto no PNE, do que temos definido de "ensino médio integrado" e EJA integrada, mesmo que predominantemente no seu sentido formal, deixa espaço para a luta fecunda em direção àquela concepção.

Portanto, os avanços e as conquistas não são poucos, considerando que nossa sociedade é marcada pela cultura escravocrata e pela história de negação do direito à educação de qualidade à classe trabalhadora. Entretanto, como apresentamos na introdução deste texto, avanços no plano jurídico não significam, imediata e absolutamente, avanços no plano ético-político. A legislação é expressão das disputas e sua consecução significa que consensos foram construídos. Isto, ao mesmo tempo que pode acomodar os conflitos, pode também gerar novas contradições na luta por hegemonia. Cada classe buscará valer-se da imperfeição de uma lei ou documento oficial em benefício se seus interesses. Significa, então, a continuidade das disputas; a fecundidade das conquistas neste plano vem daí.

Assim, há que se reconhecer que avanços neste plano não são pouco significativos se esses convergem ou potencializam contradições virtuosas para o projeto da classe trabalhadora. Mas, para que a legislação se constitua em instrumento de disputa por hegemonia, é preciso nos apropriarmos dela não somente nos seus aspectos formais, mas, especialmente, em sua historicidade e no que elas condensam e provocam a luta de classes.

Foi com essas preocupações que apresentamos nossa análise. Para além de destacarmos os avanços, procuramos abordar as dimensões pública e privada da política educacional e demonstramos o quanto os interesses e as práticas privatistas são ainda hegemônicas. Além da resistência da classe dominante e dirigente ao direito dos trabalhadores à educação pública, gratuita e de qualidade, esses dissimulam seus interesses mercantis com mecanismos de cooperação e parceria com a estrutura pública. O Estado, por sua vez, por condensar correlação de forças sob a hegemonia do capital, defendem que, em nome do emergencial, das demandas imediatas e legítimas da população pela educação e, em particular, pela educação profissional, justifica-se o repasse de recursos públicos a grande e poderosos grupos empresariais da educação. Para isto, as forças conservadoras foram exitosas em inserir no PNE uma incoerência no financiamento público da educação pública, ao permitir que este seja substituído pelo conceito de investimento total em educação, agregando-se aos investimentos os recursos advindos de programas que permitem seu uso privado.. 
Esforçamo-nos em apresentar dados de oferta de vagas na educação profissional nos últimos dez anos, com ênfase no período a partir de 2011, quando se institui o Pronatec. Ironicamente, em nome de interesses da classe trabalhadora, os números demonstram que o Estado brasileiro alimenta os lucros dos empresários da educação; prioriza a oferta da formação curta e instrumental, é condescendente com o Sistema $\mathrm{S}$ ao ignorar que o acordo de gratuidade de matrículas ocorre predominantemente com esta forma de oferta - de baixo custo, mais simples e de alta rotatividade -; e assume que a política de ensino médio integrado, de fato, não é a prioridade.

O avanço, então, está no fato de a classe trabalhadora ter mais acesso à educação do que em outros momento da história; porém esta continua sendo de qualidade relativa e não garante a apropriação dos fundamentos científico-tecnológicos, históricos, sociais e políticos da produção material e cultural que a humanidade conquistou. Tampouco poderíamos nos referir à prioridade de uma política de formação profissional que, mesmo não tendo este princípio, pudesse ser útil mais amplamente às demandas técnicas e tecnológicas da produção moderna, no patamar da atual base científica, posto que predomina a formação para o trabalho simples.

Como demonstramos, não escapam, porém, aos cuidados dos intelectuais do capital, a preocupação com um tipo de educação que forme personalidades adaptáveis - produtiva e improdutivamente - às instabilidades da vida contemporânea e à lógica flexível da acumulação capitalista. Por isto procuramos não delimitar nossa análise à educação profissional, mas discutir também a educação básica, desde a educação infantil, e as relações entre os níveis e modalidades de ensino.

Se este balanço pode nos ajudar a nos apropriar das mediações fundamentais da luta histórica pelo direito à educação da classe trabalhadora, reitera-se a necessidade de aprofundamento dos estudos e da potencialização do conhecimento disponível como força material para a manutenção das disputas. Igualmente, investir nas discussões e na construção de estratégias para o controle do cumprimento das metas do Plano, bem como na conversão de suas contradições internas em benefício da educação pública, democrática, gratuita, laica e de qualidade social, parece-nos ser uma função preponderante a ser assumida pelos educadores críticos que ainda conseguem impedir que a política educacional seja total e irrevogavelmente apropriada pelo capital.

\section{REFERÊNCIAS BIBLIOGRÁFICAS}

1. BRASIL. Decreto n. 5.154, de 23 de julho de 2004. Brasília, 2004. Disponível em http://www.planalto.gov.br/ccivil_03/_ato2004-2006/2004/decreto/d5154.htm. Consulta em 11/09/2015.

2. BRASIL. Lei n. 11.741, de 16 de julho de 2008. Brasília, 2008. Disponível em http://www.planalto.gov.br/ccivil_03/_Ato2007-2010/2008/Lei/L11741.htm. Consulta em 11/09/2015.

3. BRASIL. Emenda Constitucional n. 59, de 11 de novembro de 2009. Brasília, 2009. Disponível em http://www.planalto.gov.br/ccivil_03/Constituicao/Emendas/Emc/emc59.htm. Consulta em 11/09/2015. 
4. BRASIL. Lei n. 3.005, de 25 de junho de 2014. Brasília, 2014b. Disponível em http://www.planalto.gov.br/ccivil_03/_ato2011-2014/2014/lei/l13005.htm. Consulta em 11/09/2015.

5. BRASIL. Lei n. 11.195, de 18 de 18 de novembro de 2005. Brasília, 2005. Disponível em http://w BRASIL. Decreto n. 5.154, de 23 de julho de 2004. Brasília, 2004. Disponível em http://www.planalto.gov.br/ccivil_03/_ato2004-2006/2004/decreto/d5154.htm. Consulta em 11/09/2015ww.planalto.gov.br/ccivil_03/_Ato2004-2006/2005/Lei/L11195.htm. Consulta em 11/09/2015.

6. BRASIL. Lei n. 12.513, de 26 de outubro de 2011. Brasília, 2011. Disponível em http://www.planalto.gov.br/ccivil_03/_ato2011-2014/2011/lei/l12513.htm. Consulta em 11/09/2015.

7. BRASIL. Lei n. 12.814, de 05 de junho de 2013. Brasília, 2013. Disponível em http://www.planalto.gov.br/ccivil_03/_ato2011-2014/2013/Lei/L12816.htm. Consulta em 11/09/2015.

8. BRASIL. Plano Nacional de Educação 2014-2024 [recurso eletrônico] : Lei no 13.005, de 25 de junho de 2014, que aprova o Plano Nacional de Educação (PNE) e dá outras providências. Brasília : Câmara dos Deputados, Edições Câmara, 2014a.

9. BRASIL. SAE. Pátria educadora: a qualificação do ensino básico como obra de construção nacional. Brasília, $2015 . \quad$ Disponível em https://www.fe.unicamp.br/patriaeducadora/documento-sae.pdf. Consulta em 11/09/2015.

10. BRASIL. MEC. CNE. Parecer n. 11, de 10 de maio de 2000. Diretrizes Curriculares Nacionais para a Educação de Jovens e Adultos. Brasília, 2000. Disponível em

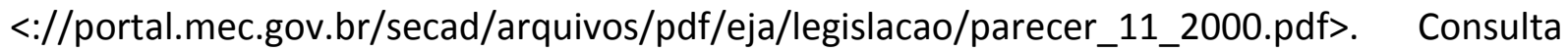
em 11/09/2015.

11. BRASIL. MEC. SETEC. Educação Profissional Técnica de Nível Médio integrada ao Ensino Médio. Documento Base. Brasília, 2007.

12. BRASIL. MEC. SETEC. Prestação de Contas Ordinária: relatório de gestão 2010. Disponível em:<http://portal.mec.gov.br/index.php?ltemid=1064\&id=14945\&option=com_content\&vie $\mathrm{w}=$ article $>$ Acesso em: 30/1/2011.

13. BRASIL. MEC. SETEC. Relatório de Gestão do Exercício de 2011. Brasília, 2012. Disponível em file://C:/Users/Laeps02/Downloads/relatorio_gestao_setec_2011\%20(2).pdf. Consulta em 18/07/2014.

14. BRASIL. MEC. SETEC. Relatório de Gestão do Exercício de 2012. Brasília, 2013. Disponível em file:///C:/Users/Laeps02/Downloads/relatorio_gestao_da_setec_exercicio_2012\%20(9).pdf. Consulta em 18/07/2014.

15. BRASIL. MEC. SETEC. Relatório de Gestão do Exercício de 2013. Brasília, 2014. Disponível em file:///C:/Users/Laeps02/Downloads/relatorio_gestao_exercicio_2013_setec.pdf. Consulta em 18/07/2014.

16. BRASIL. MEC. Portaria n. 160, de 05 de março de 2013. D.O.U. № 45, quinta-feira, 7 de março de $2013 . \quad$ Disponível em http://portal.mec.gov.br/index.php?option=com_docman\&view=download\&alias=12650portaria-160-08032013-pdf\&category_slug=marco-2013-pdf\&Itemid=30192. Consulta em $11 / 09 / 2015$.

17. CNTE. Cadernos de Educação / Confederação Nacional dos Trabalhadores em Educação (CNTE). Ano XVIII, n.28, nov. 2014, 2a Edição Ampliada. Brasília.

18. GUIMARÃES, C. Caminhos e desencontros de uma Pátria Educadora. Revista POLI: saúde, educação e trabalho - jornalismo público para o fortalecimento da Educação Profissional em 
Saúde. . Ano VII - № 41 - jul./ago. 2015. Diponível em www.epsjv.fiocruz.br. Consulta em $11 / 09 / 2015$.

19.

- Capital financeiro avança sobre a educação profissional. POLI: saúde, educação e trabalho. Ano VI, no 35, p. 14 - 16, jul/ago. 2014a. Diponível em WWW.epsjv.fiocruz.br. Consulta em 11/09/2015.

20. GRAMSCl, A. O Moderno Príncipe: Maquiavel e o Estado Moderno. Rio de Janeiro: Civilização Brasileira, 1991a.

21. . Os intelectuais e a organização da cultura. Rio de Janeiro: Civilização Brasileira, 1991b.

22. INEP. Sinopse estatística da educação básica: censo escolar 2003. Instituto Nacional de Estudos e Pesquisas Educacionais Anísio Teixeira: Brasília, 2003. Disponível em http://portal.inep.gov.br/básica-censo-escolar-sinopse-sinopse>. Consulta em 14/07/2014

23. INEP. Sinopse estatística da educação básica: Disponível em http://portal.inep.gov.br/básicacenso-escolar-sinopse-sinopse>. Consulta em 14/07/2014.

24. INEP. Censo da educação básica: 2012 - resumo técnico. Brasília: Instituto Nacional de Estudos e Pesquisas Educacionais Anísio Teixeira, 2013. Disponível em http://download.inep.gov.br/educacao_basica/censo_escolar/resumos_tecnicos/resumo_te cnico_censo_educacao_basica_2012.pdf. Consulta em 14/07/2014.

25. KOSIK, K. Dialética do Concreto. São Paulo: Paz e Terra, 1978.

26. NOSELLA, P. ÉTICA E PESQUISA. Educ. Soc., Campinas, vol. 29, n. 102, p. 255-273, jan./abr. 2008257 Disponível em www.cedes.unicamp.br. Consulta em 11/09/2015.

27. POULANTZAS, Nicos. As lutas políticas: o Estado, condensação de uma relação de forças. In: 0 Estado, o poder, o socialismo. 3aed. Rio de Janeiro: Graal, 1985.

28. RAMOS, $M, N$. Filosofia da práxis e práticas pedagógicas de formação de trabalhadores. Trabalho \& Educação (UFMG), v. 23, p. 207-218, 2014.

29. . Implicações Políticas e Pedagógicas da EJA integrada à Educação Profissional. Educação e Realidade, v. 35, p. 65-85, 2010.

30. SAVIANI, D. A nova lei da educação. LDB, limite, trajetória e perspectivas. $8^{a}$. ed. São Paulo: Autores Associados, 1997. 